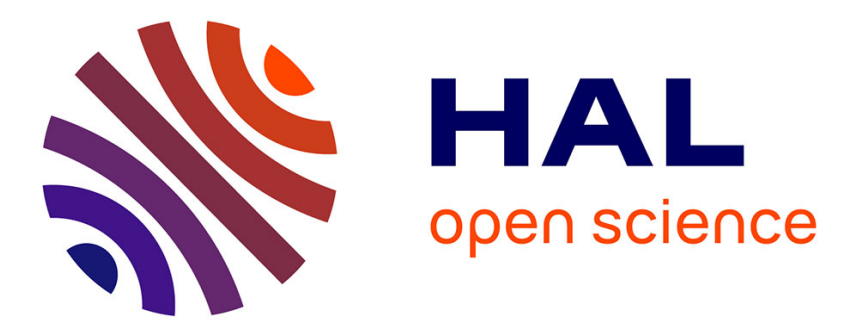

\title{
Iron-Strapped Porphyrins with Carboxylic Acid Groups Hanging over the Coordination Site: Synthesis, X-ray Characterization, and Dioxygen Binding
}

Bernard Boitrel, Ismail Hijazi, Thierry Roisnel, Koji Oohora, Takashi Hayashi

\section{- To cite this version:}

Bernard Boitrel, Ismail Hijazi, Thierry Roisnel, Koji Oohora, Takashi Hayashi. Iron-Strapped Porphyrins with Carboxylic Acid Groups Hanging over the Coordination Site: Synthesis, Xray Characterization, and Dioxygen Binding. Inorganic Chemistry, 2017, 56 (13), pp.7373-7383. 10.1021/acs.inorgchem.7b00343 . hal-01560306v2

HAL Id: hal-01560306

https://hal-univ-rennes1.archives-ouvertes.fr/hal-01560306v2

Submitted on 14 Sep 2017

HAL is a multi-disciplinary open access archive for the deposit and dissemination of scientific research documents, whether they are published or not. The documents may come from teaching and research institutions in France or abroad, or from public or private research centers.
L'archive ouverte pluridisciplinaire $\mathbf{H A L}$, est destinée au dépôt et à la diffusion de documents scientifiques de niveau recherche, publiés ou non, émanant des établissements d'enseignement et de recherche français ou étrangers, des laboratoires publics ou privés. 


\title{
Iron-Strapped Porphyrins with Carboxylic Acid Groups Hanging over the Coordination Site: Synthesis, X-ray Characterization, and Dioxygen Binding
}

\author{
Bernard Boitrel $^{* \dagger}$, Ismail Hijazi ${ }^{\dagger}$, Thierry Roisnel ${ }^{\dagger}$, Koji Oohora ${ }^{\ddagger}$, and Takashi Hayashi ${ }^{* \ddagger}$ \\ ${ }^{\dagger}$ Institut des Sciences Chimiques de Rennes, UMR CNRS 6226, Université de Rennes 1, \\ 35042 Rennes Cedex, France \\ ${ }^{\ddagger}$ Department of Applied Chemistry, Graduate School of Engineering, Osaka University, \\ Yamadaoka 2-1, Suita, Osaka 565-0871, Japan
}

Corresponding author: bernard.boitrel@univ-rennes1.fr. Fax: +33(2)2323 5637. Phone: +33(2)2323 5856., *E-mail: thayashi@chem.eng.osaka-u.ac.jp. 


\section{ABSTRACT}

A series of myoglobin active site analogues was synthesized and characterized to investigate the dioxygen binding effects of having a flexible distal strap over the coordination site. These four synthetic models differ mostly by the shape and polarity of their cavities and possibly also by motion of the distal strap attached to two of the meso carbon atoms. Each of the four models has an intramolecular nitrogen base that axially binds the iron(II) cation inside the porphyrin but they differ either by the nature of the distal strap or by its mobility. The overhanging distal group is either a generally apolar ethyl malonate group or a polar malonic acid group which is also a strong H-bond donor. It is shown that in the ferrous complex $\mathbf{2 b}$ bearing such an overhung malonic acid group in close proximity to the iron atom, the equilibrium rate for dioxygen binding is significantly enhanced in comparison to its ester precursor. In the case of the analogous complex $\mathbf{1 b}$ bearing a more mobile distal strap, one of the carboxylic acid group binds the iron(II) cation, leading to a six-coordinate ferrous complex. Unexpectedly, this complex proved to be high-spin $(S=2)$ as shown by solid state magnetic measurements. Whereas this unprecedented complex still binds dioxygen, the formation of the intramolecular six-coordinate complex precluded the measurement of its dioxygen affinity through direct quantitative gas titration monitored by UV-vis spectroscopy. However, in this case, the determination of the kinetic rate constants for dioxygen binding and dissociation by laser flash photolysis allowed evaluation of the equilibrium rate. Together with three previous X-ray structures of iron complexes in the $\alpha \alpha \beta \beta$ conformation, the structure of the cavity and the shape of the relaxed distal strap are also discussed with consideration of the resolution of X-ray structures of two different free-base ligands in the $\alpha \alpha \beta \beta$ conformation, one bearing the ethyl malonate group and the second one bearing the malonic acid group. A third X-ray structure of the analogous ligand with the overhanging ethyl malonate group in the $\alpha \beta \alpha \beta$ series allows a direct comparison of the distal strap in both geometries. This work reveals that the compound with the overhanging carboxylic acid group which cannot directly interact with the ferrous heme exhibits an increased dioxygen affinity by two orders of magnitude versus its ester precursor. 


\section{KEYWORDS}

iron porphyrins, six-coordinate, high-spin, X-ray structure, dioxygen binding.

\section{INTRODUCTION}

For at least four decades now, researchers have been investigating the mechanism of $\mathrm{CO}$ and $\mathrm{O}_{2}$ discrimination in natural hemoproteins, such as myoglobin $(\mathrm{Mb})$ and hemoglobin $(\mathrm{Hb}) .{ }^{1}$ These hemoproteins store and carry dioxygen in the presence of the endogenous carbon monoxide with a ratio of affinity of approximately 200. For synthetic heme, this ratio is much higher, up to 20000 . It has long been assumed that the $\mathrm{CO} / \mathrm{O}_{2}$ discrimination is mainly based on distal steric constraints prescribed on CO binding (this is known as the Collman hypothesis). ${ }^{2}$ Indeed, this hypothesis explains how nature has solved the problem of carbon monoxide toxicity without steric hindrance of $\mathrm{O}_{2}$ binding as the latter binds in a bent fashion. ${ }^{3}$ However, there is still an ongoing debate about the nature and molecular mechanism of this discrimination. Another way to increase the discrimination of $\mathrm{CO}$ is to increase the affinity for binding of dioxygen. The most significant distal effect to achieve such an increase is the stabilization of the bound dioxygen in $\mathrm{Mb}$ and $\mathrm{Hb}$ by hydrogen bonding with the distal histidine residue (this is known as the Pauling hypothesis). ${ }^{4}$ This hydrogen bonding has been confirmed later by neutron diffraction measurements of the oxy-myoglobin complex itself. ${ }^{5}$ Synthetic models of $\mathrm{Mb}$ have been invaluable in unravelling the subtle and correct balance between reversible dioxygen binding and its potential competitor, carbon monoxide. ${ }^{6}$ The very first milestone in the domain of synthetic mimics of Mb was the "picket-fence" porphyrin which still today, remains the only model of oxy-myoglobin isolated and characterized in the solid state. ${ }^{7}$ With this molecule it was established that dioxygen affinities similar to those of natural proteins could be reached because the picket fence prevents formation of the $\mu$-oxo-dimer. Since then, many other models have been developed and studied to investigate the possible influences of steric and polar interactions on gas binding. Examples of such models include capped, ${ }^{8}$ pocket, ${ }^{9}$ hybrid, ${ }^{10}$ basket-handle ${ }^{11}$ and aza-tripodal capped ${ }^{12}$ porphyrins. Thus, 
it has been established that systematically decreasing the size of the distal cavity decreases CO affinity without a significant effect on $\mathrm{O}_{2}$ affinity. This effect has been rationalized mainly by a decreased ligand-association rate constant of the linear bound CO. On the other hand, few reports deal with the possible influence of electrostatic interactions on $\mathrm{CO}$ binding and thus on its discrimination. ${ }^{13}$ The latter study described successful $\mathrm{CO} / \mathrm{O}_{2}$ discrimination with overhanging hydroxyl groups in iron twincoronet porphyrins. In these models, the stability of the dioxygen complexes and their $\mathrm{O}_{2}$ affinities were explained by a hydrogen bond detected by RR spectroscopy. NMR and Pulse-ESR spectroscopic methods were also helpful in detecting such a bond. ${ }^{14,15,16}$ However, to the best of our knowledge, a solid-state structure of a synthetic dioxygen carrier exhibiting a hydrogen bond with the dioxygen adduct has never been reported. Thus, design, synthesis and characterization of a dioxygen carrier model with a polar group suspended over the coordination site would be a worthwhile effort. Concomitantly, an intramolecular nitrogen base should be present to stabilize of the ferrous heme as a five-coordinate complex. On the distal side, the polar group must be located at a suitable distance from the heme to first allow either dipolar interactions or hydrogen bonding with the superoxo complex without any possible direct interaction with the heme itself. The latter property has long been shown to be crucial for non sterically hindered porphyrins ${ }^{17}$ and must not be neglected for the design of any model. ${ }^{18}$ Furthermore, it would be convenient to imagine a structure that could avoid steric hindrance while retaining the polar group near the bound dioxygen. This implies the synthesis and characterization of not one but rather several models that would allow such a variation and represents the main focus of this work.

In a preliminary communication, we reported the dioxygen binding constants measured on two isomeric series of iron strapped porphyrins. ${ }^{19}$ Each series contains two models differing only by the nature of the overhanging group, either a diethyl malonate moiety or a malonic acid moiety. In one series, the porphyrin bearing the malonic acid exhibits a dioxygen affinity 100 times higher than its diethyl ester counterpart. In the second series, the porphyrin bearing the malonic acid proved to evolve slowly from the initial five-coordinate complex to the six-coordinate complex as a result of intramolecular 
coordination of the malonic acid, precluding the direct measurement of the equilibrium rate. ${ }^{20}$ For this precise model, we have thus investigated the dioxygen binding behavior using laser flash photolysis to obtain deeper insights into the kinetic rates together with X-ray characterization of the three novel ligands described herein.

\section{EXPERIMENTAL SECTION}

Materials and Methods. All commercials chemicals (Aldrich, Acros) and solvents (ACS for analysis) were used without further purification unless otherwise stated. Solvents used in an inertatmosphere (dry-box; $\left.\left[\mathrm{O}_{2}\right]<1 \mathrm{ppm}\right)$ were freshly distilled and deoxygenated by three "freeze-pump" cycles. Benzene, toluene and THF were distilled over potassium benzophenone ketyl; methylene chloride, pyridine, triethylamine and pentane over $\mathrm{CaH}_{2}$; methanol over magnesium turnings. Column chromatography was performed on $\mathrm{SiO}_{2}$ (Merck TLC-Kieselgel 60H, $15 \mu \mathrm{m}$ ). ${ }^{1} \mathrm{H}$ NMR spectra were recorded on a BrukerAvance500 or spectrometer equipped with a TBI probe. Spectra were referenced with residual solvent protons. UV/ Vis spectra were recorded on a Uvikon XL spectrometer. X-Ray data were collected on an APEXII, Bruker-AXS diffractometer. Kinetic measurements of $\mathrm{O}_{2}$ association were carried out using a laser flash photolysis system constructed by Unisoku, CO., Ltd (Osaka, Japan). A Xe arc lamp was employed as the source of the probe light to follow the spectral changes and a sample was excited with $5 \mathrm{~ns}$ pulses $(532 \mathrm{~nm})$ from a Q-switched Nd: YAG laser (Surelite I, Continuum).

Synthesis and Characterization. Porphyrins 1a, $\mathbf{1 b}$ and $4,{ }^{19}$ porphyrins 5 and $\mathbf{6},{ }^{21}$ and porphyrins $\mathbf{7}, \mathbf{8}, \mathbf{2} \mathbf{a}$, and $\mathbf{2} \mathbf{b}^{22}$ were prepared as previously reported.

Laser flash photolysis studies. The association of $\mathrm{O}_{2}$ was confirmed by observation of absorbance changes of the Soret bands after the flash photolysis of MP.B. $\mathrm{O}_{2}$ under various partial pressures of $\mathrm{O}_{2}$ at 
$25^{\circ} \mathrm{C}$. Each time course of the absorbance was analyzed by single phase kinetics to give a pseudo-firstorder rate constant $\left(k_{\mathrm{obs}}\right)$. The association rate constant of $\mathrm{O}_{2}$ for MP.B. $\left(k_{\mathrm{O} 2}^{\mathrm{on}}\right)$ is determined by the following equation:

$$
k_{\mathrm{obs}}=k_{\mathrm{O} 2}^{\mathrm{on}}\left[\mathrm{O}_{2}\right]+k_{\mathrm{O} 2}^{\mathrm{off}}
$$

where $k^{\text {off }}{ }_{\mathrm{O} 2}$ is the dissociation rate constant of $\mathrm{O}_{2}$ for MP.B. Dioxygen solubility in benzene at $25^{\circ} \mathrm{C}$ is $9.1 \times 10^{-3} \mathrm{M} \mathrm{atm}^{-1}$. For $\mathbf{1 b F e}$, only the apparent $k_{\mathrm{O} 2}^{\text {off }} k^{\text {off }}{ }_{\mathrm{O} 2}$, can be evaluated because intercept of the plots of $k_{\text {obs }}$ against $\mathrm{O}_{2}$ concentration includes $k^{\text {off }}{ }_{2}$ and the rate constants for intramolecular association and dissociation, $k_{L}^{\text {on }}$ and $k_{L}^{\text {off }}$, respectively (Scheme $\mathrm{S} 1$ ). The intercept value is too small and almost zero (Figure S3). Thus, an expected upper limit of the $k^{\mathrm{off}} \mathrm{O}$ was determined from the experimental deviation. In the case of $\mathbf{2} \mathbf{b F e}$, the association of $\mathrm{O}_{2}$ is slightly faster than limitations of our instrument even under a low partial pressure $(0.1 \mathrm{~atm})$ of $\mathrm{O}_{2}$. Thus, an expected lower limit of the $k^{\text {on }}{ }_{\mathrm{O} 2}$ was determined.

\section{X-ray Crystallographic Studies.}

The crystals of the three compounds were grown as indicated here after.

1b: Slow diffusion of a mixture of $\mathrm{MeOH} / \mathrm{H}_{2} \mathrm{O}$ in a DMF solution of the compound.

2a: Slow evaporation of a mixture of $\mathrm{CHCl}_{3} / \mathrm{MeOH}$ in which the compound is dissolved.

4: Slow evaporation of a mixture of $\mathrm{CHCl}_{3} / \mathrm{MeOH} /$ Acetone in which the compound is dissolved.

Crystallographic data (excluding structure factors) for the structures reported in this paper have been deposited with the Cambridge Crystallographic Data Center as supplementary publication nos. CCDC792739 (1b), CCDC 993981 (2a), and CCDC 792738 (4). Copies of the data can be obtained free of charge by contacting the CCDC, 12 Union Road, Cambridge CB2 1EZ, U.K. (fax, (international) + 44-1223/336-033; e-mail, deposit@ccdc.ca-m.ac.uk). The structures were solved by direct methods using the SIR97 program, ${ }^{23}$ which revealed all of the non-hydrogen atoms, and refined with full-matrix 
least-square methods based on $F 2(S H E L X-97)^{24}$ with the aid of the WINGX19 ${ }^{25}$ program. All nonhydrogen atoms were refined with anisotropic thermal parameters. Hydrogen atoms were finally included in their calculated positions. 


\section{RESULTS AND DISCUSSION}

A series of four ferrous porphyrins $\mathbf{1 a F e}, \mathbf{1 b F e}, \mathbf{2 a F e}$ and $\mathbf{2 b F e}$ (Figure 1) were synthesized according to a previously reported method. ${ }^{26}$ The method is based on the reaction of diethyl malonate with picket porphyrins obtained by reaction of 3-chloromethyl benzoyl chloride on various atropisomers of tetra-2aminophenyl porphyrin (TAPP). ${ }^{7 \mathrm{a}}$ Further reaction of a nucleophilic reagent as a malonate carbanion or a primary amine on the resulting picket porphyrins leads to the formation of straps. Thus the geometry of these bis-strapped porphyrins depends on the selected atropisomer of TAPP as starting material. In this work, we focused on both $\alpha-5,15-\beta-10,20$ and $\alpha-5,10-\beta-15,20$ bis-strapped porphyrins. Among the four compounds studied, those labeled $\mathbf{1}$ represent the $\alpha \alpha \beta \beta$ isomer and compounds labeled $\mathbf{2}$ represent the $\alpha \beta \alpha \beta$ isomer. Compounds labeled a possess an ethyl malonic ester group and those labeled $\mathbf{b}$ possess a malonic acid group, while all other features are otherwise the same. This series allows us to conduct a cross comparison of both the nature of the distal hanging group and the geometry of the compound.
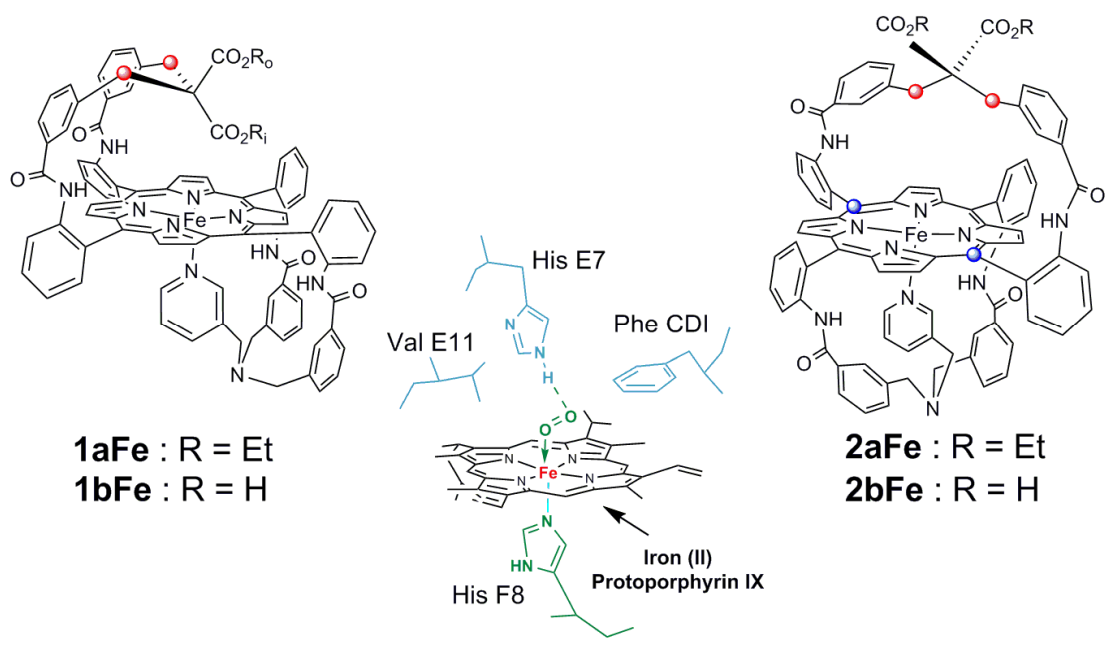

2aFe : $\mathrm{R}=\mathrm{Et}$ 2bFe : $\mathrm{R}=\mathrm{H}$

\section{Figure 1}

The key structural feature of this series is depicted in Figure 1 by the red circles of the distal strap that represent the two benzylic methylene groups. These groups act as hinges to permit a swinging motion of the overhanging group. This swinging motion does not have a strong influence on the spatial location of 
the overhanging group of compounds 2 in the $\alpha \beta \alpha \beta$ series. However, for compounds $\mathbf{1}$ of the $\alpha \alpha \beta \beta$ series, it allows the malonyl group to switch from an inner position to an outer location and thus to change the steric hindrance over the coordination binding site. For instance, the $\mathrm{R}_{\mathrm{i}}$ group can be oriented inside the binding cavity as depicted (Figure 1, compounds 1) or moved outside of the cavity upon rotation around the two benzylic methylene groups. This conformational flexibility has already been confirmed by X-ray crystallography in the coordination of large cations by this type of ligands, whether in the $\alpha \alpha \beta \beta^{27}$ or in the $\alpha \beta \alpha \beta$ conformation. ${ }^{28}$ In the latter, it should be noted that an additional possible rotation of the strap comes from its hinges which are located at opposing meso positions denoted by the blue circles in Figure 1. In other words, in model $\mathbf{2 b}$, the carboxylic acid groups can only change their orientation from outside to inside the cavity by rotation around the benzylic groups but at an invariable distance from the iron atom imposed by rotation of the strap around the 5,15 meso-position axis. Conversely, the restricted degree of freedom for the rotation of the strap in $\mathbf{1 b}$, due to its anchoring on the 5,10 meso positions offers higher control of the positioning of the potential hydrogen-bond donating group but at a variable distance from the iron(II) core. Indeed, the only change in the location of the carboxylic groups should arise from bond rotation around the benzylic carbon atoms in the strap. However, from previous X-ray structures of similar complexes with inert metal such as nickel or zinc bearing an axial ligand, we know that owing to its intrinsic flexibility, the bending of this type of strap can vary from $45^{\circ}$, bent over the coordination site to approximately $84^{\circ}$, which is close to being perpendicular to the porphyrin plane. ${ }^{27}$

We have shown that the route for synthesis of compounds of series $\mathbf{1}$ from picket porphyrin $\mathbf{5}$ is most efficient when a two-step process is used where a different strap is linked to each side of the porphyrin (Scheme 1). ${ }^{19}$ Thus, the first step consists of the synthesis of single strap porphyrin 4 prepared by addition of diethyl malonate to picket porphyrin 5 in the presence of base (60\% yield). We further solved the crystallographic structure of 4 (Figure 2 and Table 1). Actually, the compound crystallizes with two different molecules in the asymmetric unit. The two centroids of each porphyrin are separated by $16.29 \AA$ with an angle of $48.24^{\circ}$ between the two mean porphyrin planes. The two molecules 
although different exhibit the same conformation of both the strap and the two pickets. However, as in one molecule, one of the ethyl ester groups is disordered over two positions, we will refer to the other porphyrin without any disorder for the structural description. In this structure, the two remaining pickets have outwardly-directed $-\mathrm{CH}_{2}-\mathrm{Cl}$ groups where the $-\mathrm{CH}_{2}$ - groups are located inside the cavity when the strap is closed (see $\mathrm{C} 1$ and $\mathrm{C} 3$ of the strap, Figure 2). In the relaxed conformation, the strap is bent over the coordination site with an average angle of $41^{\circ}$. A typical structural feature of this strap in this particular geometry is influenced by the ethyl malonate group which is oriented inwards by rotation of the bond between benzylic carbon atoms $\mathrm{C} 1$ and $\mathrm{C} 3$ to induce the strap to adopt a clear W-shape, with a short distance between the oxygen atom of one ester group (O3) and the oxygen atom $\mathrm{O} 2$ of the carbonyl from the other ester residue $(\mathrm{O} 2-\mathrm{O} 3: 2.712 \AA)$. As a result, the $\mathrm{COO}$ group labeled $\mathrm{O} 3 \mathrm{C}_{\mathrm{o}} \mathrm{O} 4$ is closer to the porphyrin plane than that labeled $\mathrm{O}_{1} \mathrm{C}_{\mathrm{i}} \mathrm{O} 2$, with $\mathrm{O} 4$ located only $3.680 \AA$ away of the centroid of the macrocycle. This first X-ray structure is a reliable illustration of the possibility of rotation of the overhanging group around the two benzylic hinges. This specific conformation has a direct influence on the coordination properties of the resulting iron models, as described in more detail below. It is important to note that this W-shape of the strap is achieved in this case without any attractive coordination driving force and therefore represents the least constrained, or "relaxed" conformation of the strap. 


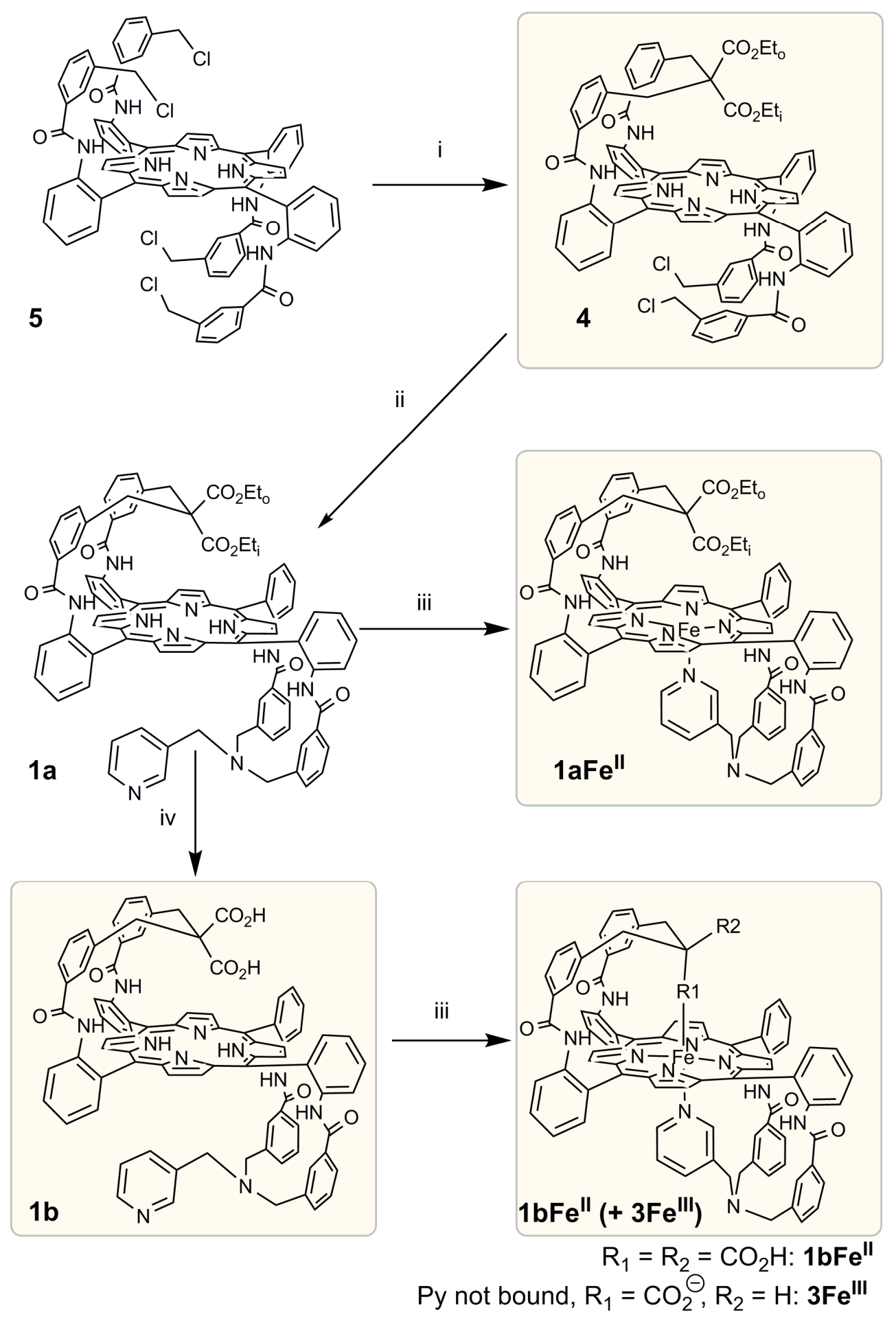

Scheme 1 


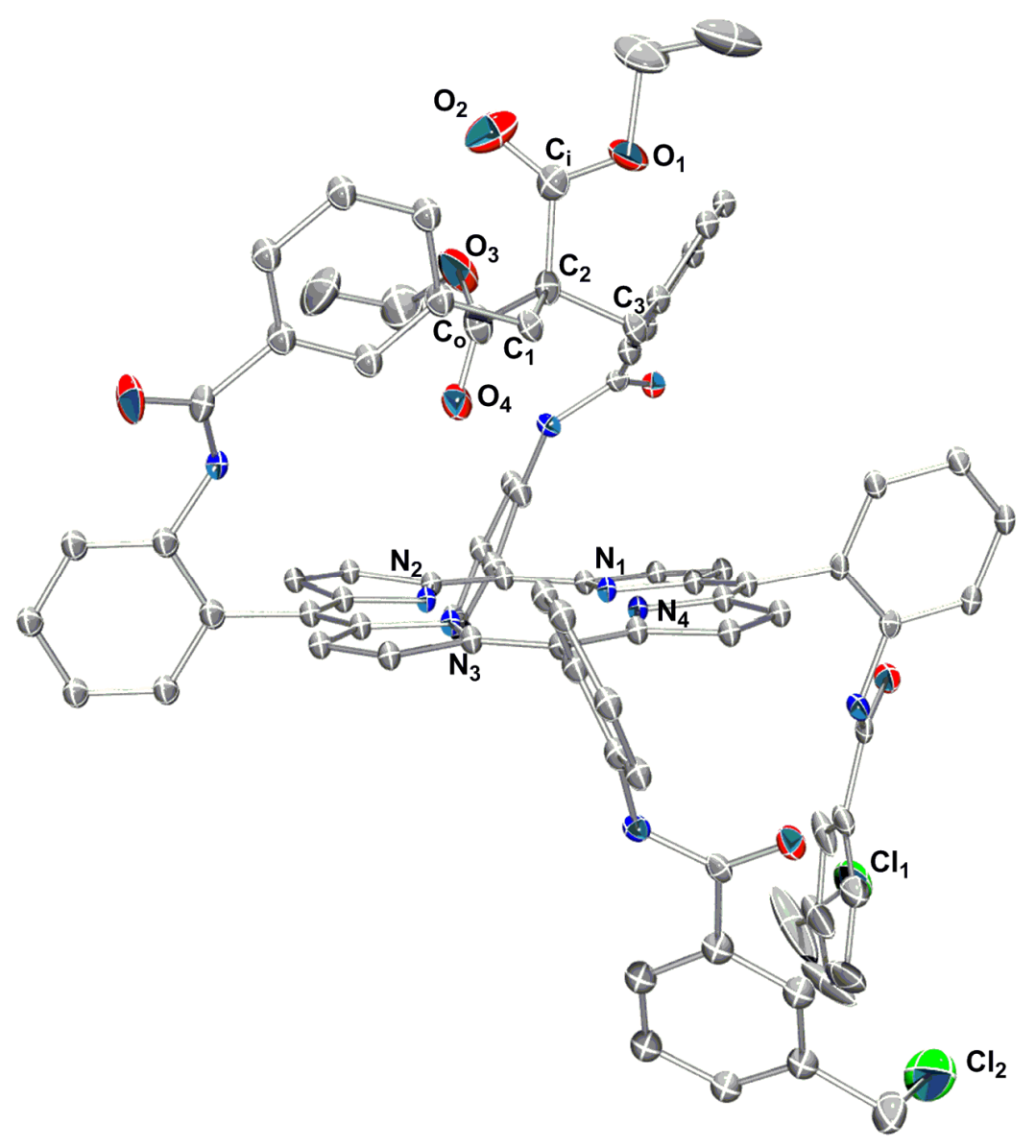

Figure 2

The next synthetic step is achieved by addition of $C$-pyridin-3-yl-methylamine to 4 leading to the expected bis-strapped ligand 1a, bearing on one side a hanging diethyl malonate moiety and on the other one a pyridinyl residue. Treatment of $\mathbf{1 a}$ with $\mathrm{BBr}_{3}$ at room temperature leads to cleavage of the ester groups while avoiding any decarboxylation to obtain porphyrin $\mathbf{1 b}$ with an overhanging malonic acid group. For this free-base ligand as well, we obtained single crystals and solved its X-ray structure (Figure 3, Table 1). 


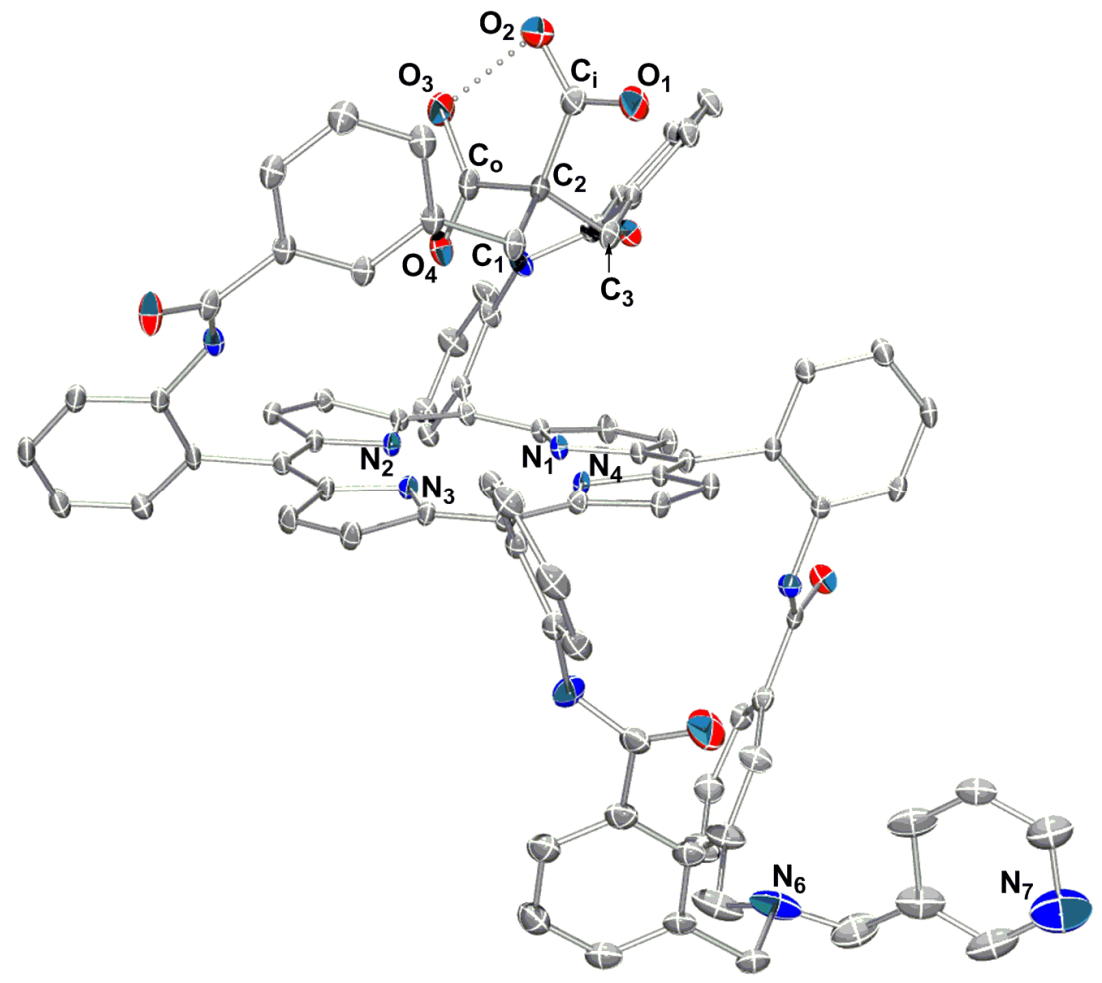

Figure 3 
Table 1

\begin{tabular}{|c|c|c|c|}
\hline & 4 & $\mathbf{1 b}$ & $\mathbf{2 a}$ \\
\hline$T, \mathrm{~K}$ & $100(2)$ & $100(2)$ & $150(2)$ \\
\hline formula & $\mathrm{C}_{83} \mathrm{H}_{64} \mathrm{Cl}_{2} \mathrm{~N}_{8} \mathrm{O}_{8}$ & $\mathrm{C}_{85} \mathrm{H}_{62} \mathrm{Fe} \mathrm{N}_{10} \mathrm{O}_{8}$ & $\mathrm{C}_{89} \mathrm{H}_{70} \mathrm{~N}_{10} \mathrm{O}_{8}$ \\
\hline formula weight & 1372.32 & 1351.45 & 1407.55 \\
\hline crystal color & red & red & red \\
\hline crystal system & triclinic & triclinic & triclinic \\
\hline space group & $\mathrm{P}-1$ & $\mathrm{P}-1$ & $\mathrm{P}-1$ \\
\hline$a, \AA$ & $17.429(2)$ & $14.8156(9)$ & $12.6344(5)$ \\
\hline$b, \AA$ & $20.708(3)$ & $16.2560(9)$ & $17.7182(7)$ \\
\hline$c, \AA$ & $21.287(3)$ & $21.2256(12)$ & $19.5499(8)$ \\
\hline$\alpha,{ }^{\circ}$ & $90.541(7)$ & $100.351(3)$ & $98.740(2)$ \\
\hline$\beta,{ }^{\circ}$ & $110.578(7)$ & $109.732(2)$ & $92.791(2)$ \\
\hline$\gamma,{ }^{\circ}$ & $90.114(7)$ & $111.819(2)$ & $110.651(2)$ \\
\hline$V, \AA^{3}$ & 7192.3(17) & $4185.9(4)$ & $4022.8(3)$ \\
\hline radiation $(\lambda, \AA)$ & Mo K $\alpha(0.71073)$ & Mo K $\alpha(0.71073)$ & Mo K $\alpha(0.71073)$ \\
\hline$Z$ & 4 & 2 & 2 \\
\hline$d_{\text {calcd }}$, g.cm ${ }^{-3}$ & 1.267 & 1.072 & 1.162 \\
\hline$\mu, \mathrm{mm}^{-1}$ & 0.154 & 0.07 & 0.076 \\
\hline$F(000)$ & 2864 & 1412 & 1476 \\
\hline no. of unique data & 30730 & 18819 & 18188 \\
\hline no. of restraints & 0 & 0 & 2 \\
\hline no. of params. refined & 1132 & 956 & 966 \\
\hline GOF on $F 2$ & 1.016 & 1.031 & 1.117 \\
\hline$R 1^{a} \quad[I>2 \sigma(I)]$ & 0.1247 & 0.0827 & 0.0754 \\
\hline$R 1^{a} \quad$ (all data) & 0.1976 & 0.1077 & 0.1133 \\
\hline$w R 2^{b} \quad$ (all data) & 0.3887 & 0.2588 & 0.2528 \\
\hline
\end{tabular}


A comparison of the X-ray structure of $\mathbf{1 b}$ and that of $\mathbf{4}$ leads to three important observations. First, the two chloro pickets of $\mathbf{4}$ appear to be placed to allow bis-substitution of the pyridyl residue, which is oriented outwards with N7 atom located $11.91 \AA$ away from the centroid of the porphyrin. This orientation is expected to be adopted without a requirement for a coordination driving force. Second, the mean plane of the proximal strap ${ }^{29}$ is essentially perpendicular to the mean plane of the porphyrin $\left(83^{\circ}\right)$. Third, the $\mathrm{W}$-shape of the distal strap is also present with an overhanging malonic acid group as the conformation of this strap is identical in $\mathbf{1 b}$ and $\mathbf{4}$. The two main differences are the presence of a hydrogen bond between the two carboxylic acid groups in 1b (O2-O3: $2.461 \AA)$ and the smaller angle of the distal strap with respect to the mean porphyrin plane in $1 \mathbf{b}\left(37^{\circ}\right)$ than in $\mathbf{4}\left(47^{\circ}\right)$. The latter observation is consistent with the observation of decreased steric hindrance when switching from the ethyl ester group to the carboxylic acid group. Thus, in the free-base $\mathbf{1 b}$, the proximal strap is oriented outwards far away from its "coordinating" conformation. It is noteworthy that the relaxed conformation of the distal strap allows one of the carboxylic groups to come very close to the centroid of the porphyrin. This is an essential condition for a possible interaction with the bound dioxygen on the iron complex. As a result of the $\mathrm{W}$-shape of the strap, the closest oxygen atom to the porphyrin centroid, $\mathrm{O} 4$, is located at a distance of only $3.53 \AA$. This slightly larger distance than in porphyrin 4 (3.53 vs. $3.26 \AA$ ) may be the result of the light saddle-shaped distortion of porphyrin $\mathbf{1 b}$ with an average shift of the $\beta$ pyrrolic carbon atoms from the 24 -atom mean plane of $\pm 0.24 \AA$.

The same synthetic pathway has been applied to the second group of compounds 2 in the $\alpha \beta \alpha \beta$ conformation (Scheme 2). However the synthesis does not start from the $\alpha \beta \alpha \beta$ atropisomer (12.5\% of the TAPP mixture) but from the $\alpha \alpha \alpha \alpha$ atropisomer for which the yield of $12.5 \%$ can be increased up to $70 \%$ of the TAPP mixture using the Lindsey procedure. ${ }^{30}$ Thus, the single-strap porphyrin 7 is prepared from picket porphyrin 6 in $61 \%$ yield. Porphyrin 7 is heated in toluene and this steric decompression step supplies porphyrin $\mathbf{8}$ in $70 \%$ yield. ${ }^{22}$ The two last steps are the same as those 
of the synthesis described herein above, involving addition of the $C$-pyridin-3-yl-methylamine to obtain porphyrin $\mathbf{2 a}$ and treatment by $\mathrm{BBr}_{3}$ to obtain porphyrin $\mathbf{2 b}$. Porphyrin $\mathbf{2 a}$ was also characterized in the solid state by X-ray crystallography (Figure 4, Table 1) and is relatively important as the unique instance in this $\alpha \beta \alpha \beta$ series.
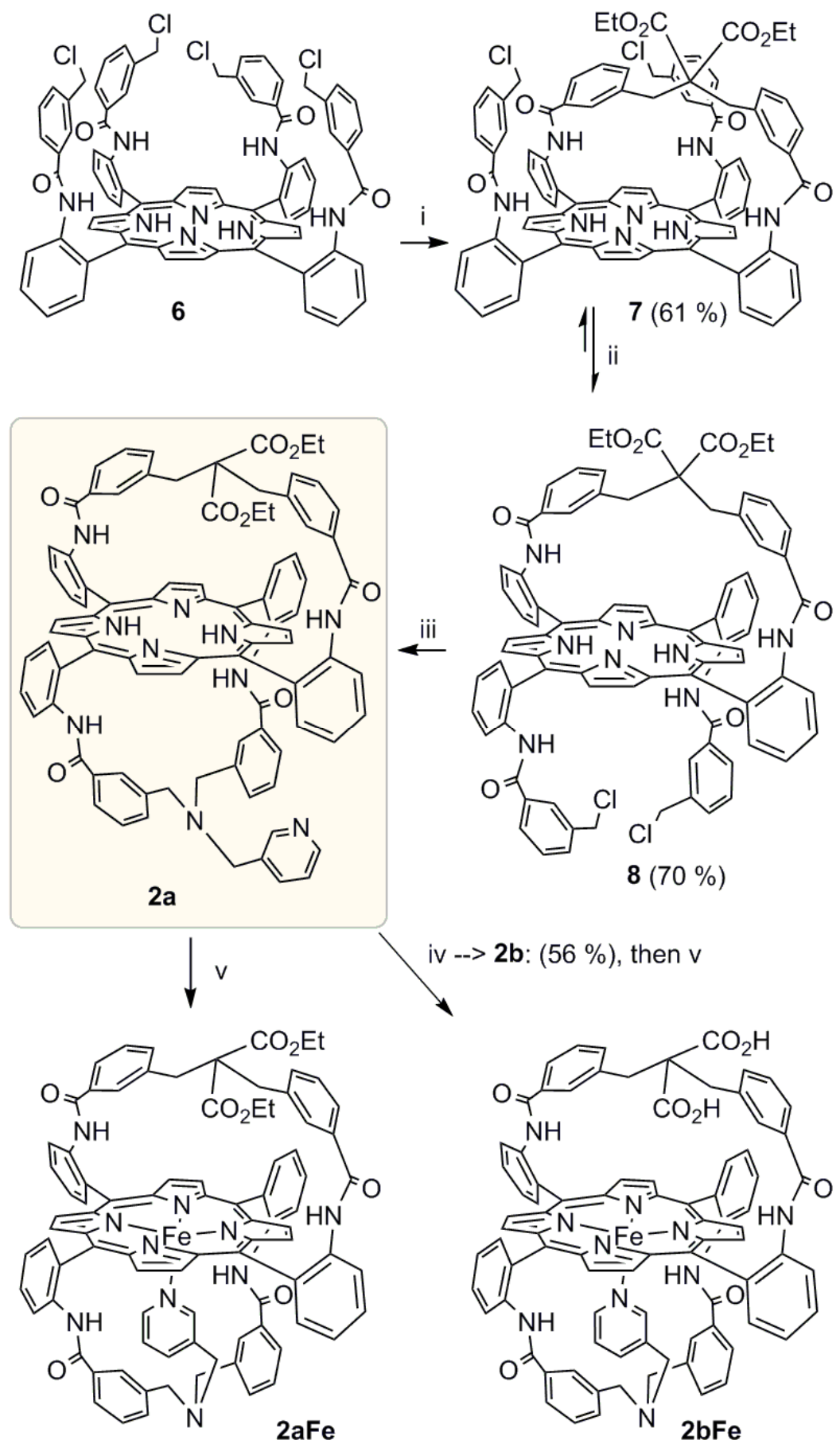

iv --> 2b: $(56 \%)$, then v

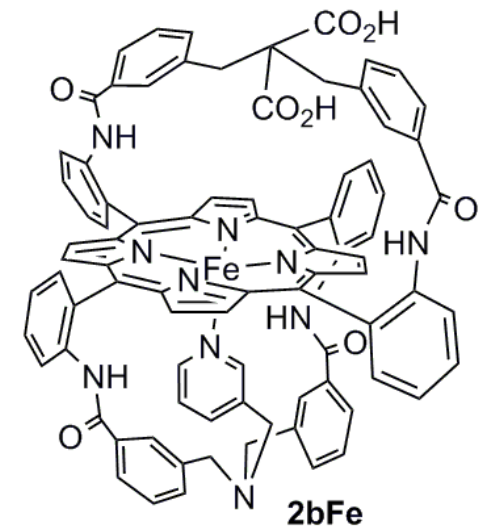

Scheme 2 


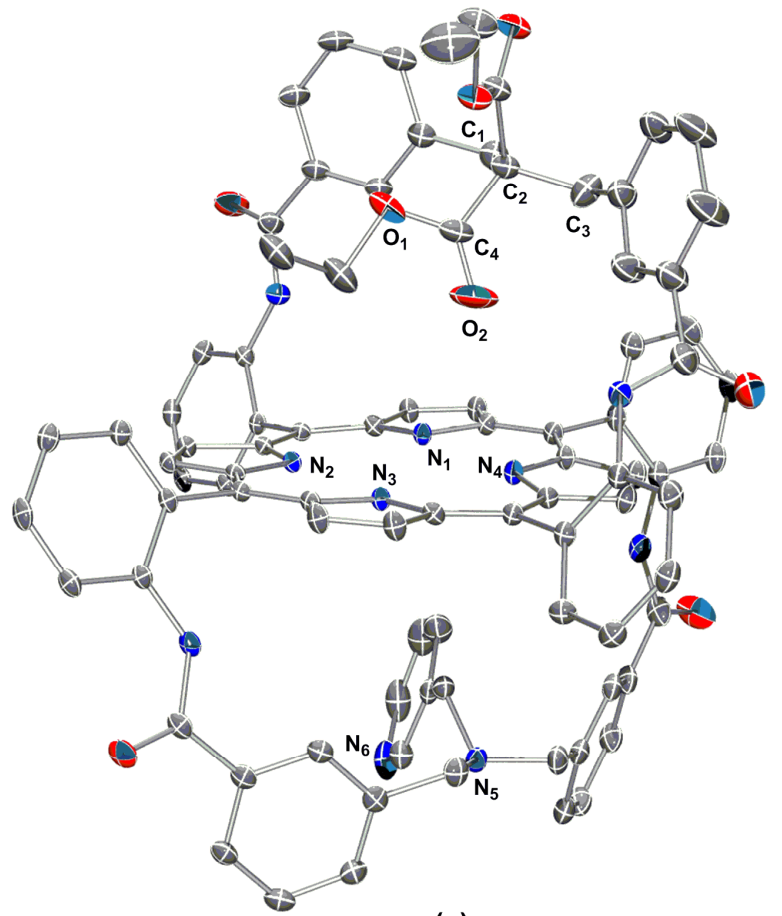

(a)

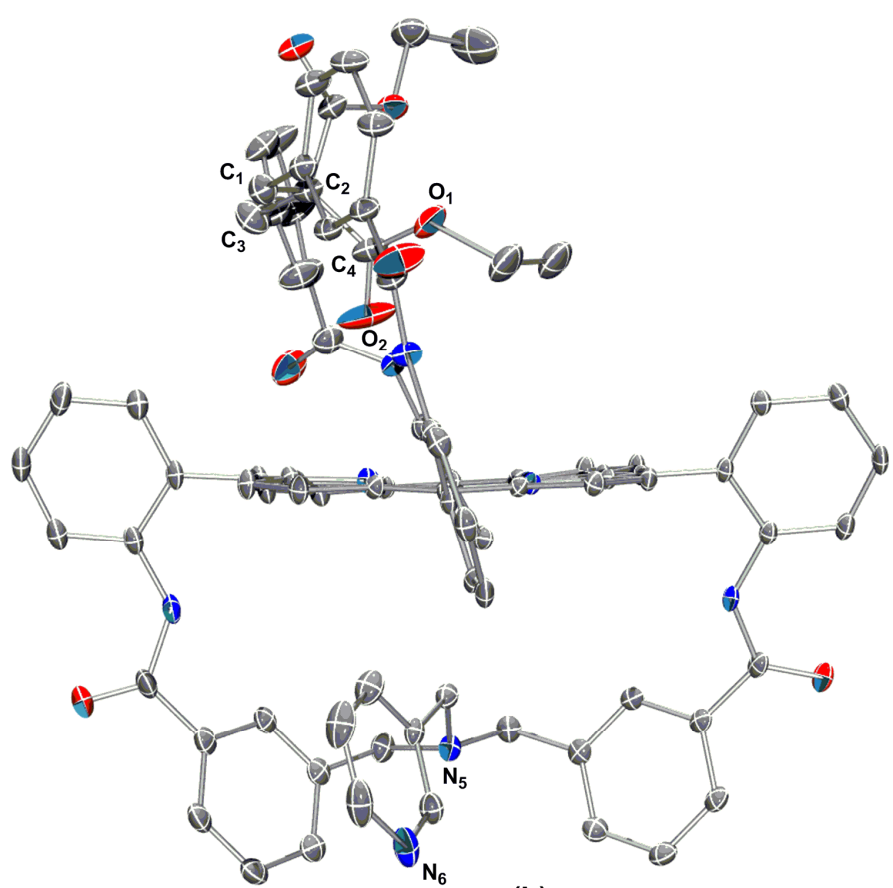

(b)

Figure 4

Although two constitutional isomers, porphyrins 1a and 2a are very different in terms of steric hindrance, rang of motion of the straps, and ligand delivery. In porphyrin $\mathbf{2 a}$, the two straps maintain an average position close to being perpendicular to the mean porphyrin plane (distal $71^{\circ}$ and proximal $77^{\circ}$ ). This is confirmed by the diethyl malonate group which exhibits only two signals for both ethyl groups that are magnetically equivalent on the proton NMR spectrum recorded at room temperature. The closest oxygen atom to the porphyrin centroid, O2, is located at a distance of $3.21 \AA$. Although the distal residue is the ester group, this distance is even shorter than the distance observed in its acid counterpart in the other geometry $\mathbf{1 b}$. However, if it can be anticipated that in compounds $\mathbf{1}$, the distance of the overhanging distal strap to the porphyrin center can change according to the angle of the distal strap to the mean porphyrin plane, this distance should remain almost essentially invariable for compound series 2. Indeed, the straps can oscillate around their bonds which are linked to the two opposed meso positions and the overhanging group can switch from a lateral position to the other equivalent lateral position by rotation around the two benzylic hinges $\mathrm{C} 1$ and $\mathrm{C} 3$. 
After iron insertion into each model inside a dry-box by heating the free-base porphyrin with iron bromide in the presence of 2,6-lutidine, the resulting complex must be carefully analyzed. It is necessary to first form a five-coordinate complex in which the nitrogen base occupies one of the two axial coordination sites because one coordination site must remain free for dioxygen binding. Typically, this can be realized in solution by either UV-vis or ${ }^{1} \mathrm{H}$ NMR spectroscopy, although the spectrum is expected to be paramagnetic as a result of the high spin $(S=2)$ character of the complex. In the solid state, X-ray characterization could unambiguously prove the nature of the complex whereas in the literature, X-ray structures are quite rare due to the inherent difficulty in handling such complexes. ${ }^{31}$

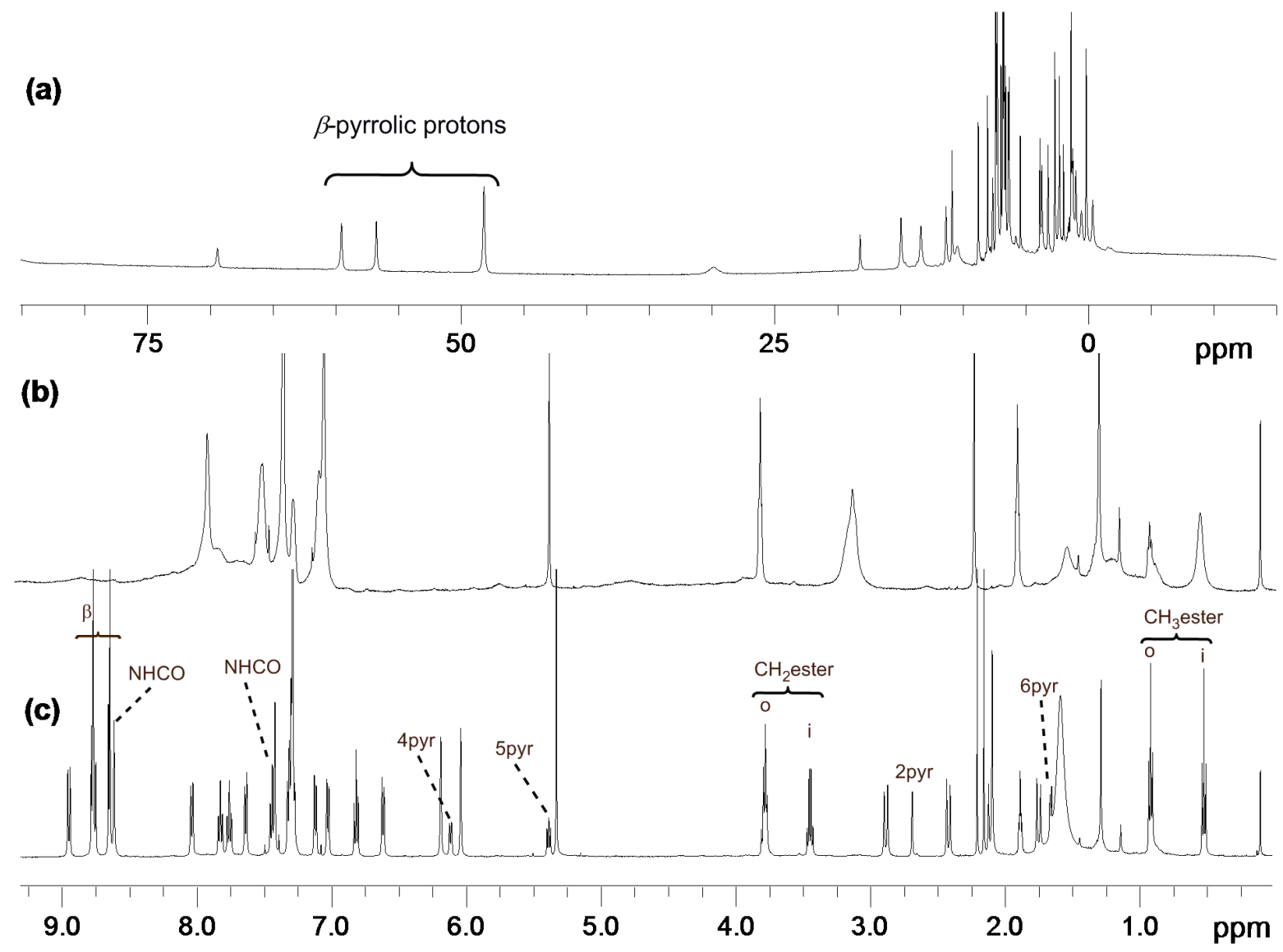

Figure 5

An example of such a five-coordinate complex is that of compound $\mathbf{1 a F e} \mathbf{e}^{\mathrm{II}}$ (Figure 5, spectrum (a)). This ${ }^{1} \mathrm{H}$ NMR spectrum is typical of a paramagnetic five-coordinate ferrous complex with chemical 
shifts for the various $\beta$-pyrrolic protons in the 50-60 ppm region. ${ }^{32}$ This sphere of coordination has been confirmed in the X-ray structure of $\mathbf{1 a F e} \mathbf{e}^{\text {II }}$ (Figure 6a). ${ }^{19}$ A second NMR spectrum was recorded after introduction of dioxygen into the NMR tube (Figure 5, spectrum (b)). This spectrum is not well resolved and exhibits broad signals. It also lacks any signal outside the usual diamagnetic region. In order to exclude the possibility of oxidation, a third NMR spectrum (Figure 5, spectrum (c)) was recorded after introduction of CO into the NMR tube. This last spectrum is well resolved with mostly sharp signals, indicating a six-coordinate diamagnetic species without any oxidation due to the preliminary binding of dioxygen. As carbon monoxide has been proposed as a reducing agent in cytochrome $c$ oxidase, ${ }^{33}$ it could also be the case in the present studies. However, in our models, we have never observed such a reaction by introduction of $\mathrm{CO}$ into the non-reduced species samples.

Based on dioxygen and carbon monoxide binding monitored by UV-vis spectroscopy (see Figure S4, supporting information), the same behavior was observed for complexes $\mathbf{2} \mathbf{a F e}$ and $\mathbf{2 b F e}$.
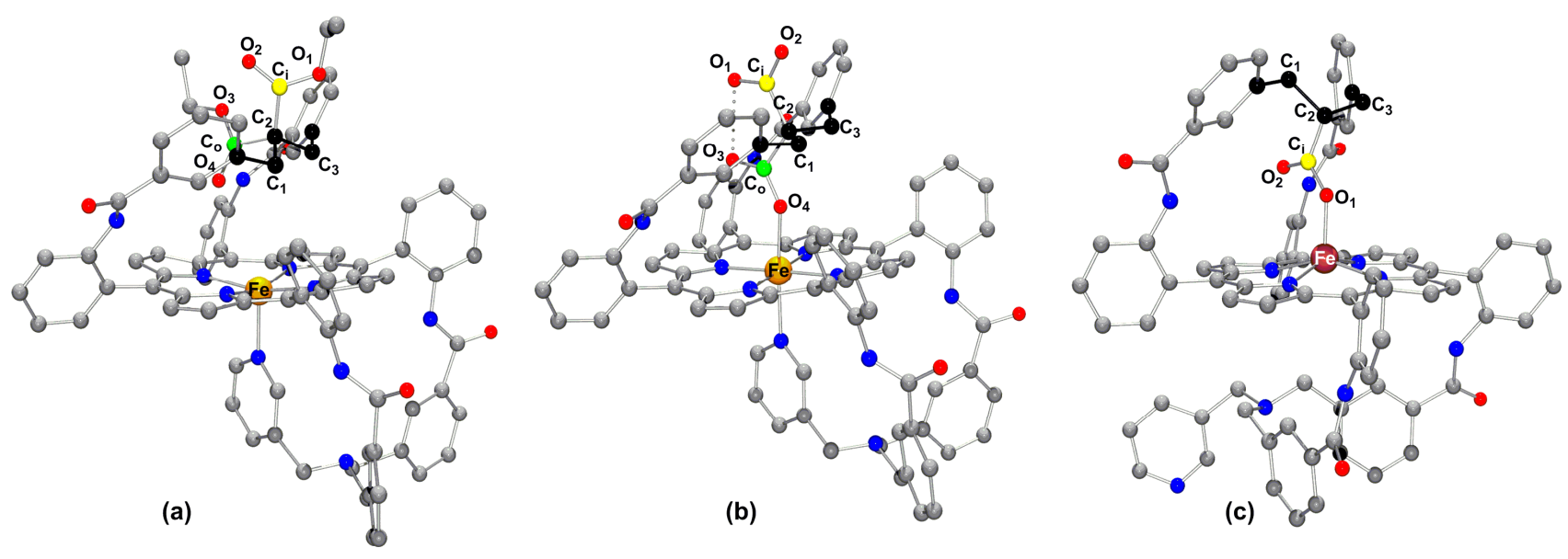

Figure 6

Thus, $\mathbf{1} \mathbf{a F e} \mathbf{I}^{\mathbf{I}}$ is a five-coordinated complex, as expected. The intramolecular pyridine is coordinated to the ferrous cation, pulled $0.430 \AA$ away from the macrocycle mean plane. The distal strap adopts the above mentioned W-shape, highlighted in black (Figure 6a) with O4, the closest oxygen atom of the distal strap to the iron atom, located at a distance of $3.602 \AA$ from the iron atom, that is chiefly at $3.2 \AA$ 
away from the mean porphyrin plane. The angle of the distal strap to the mean porphyrin plane is $33^{\circ}$. The W-shape conformation adopted by the distal strap drives the $\mathrm{O} 4$ atom inside the distal cavity where it is pinched between the two pickets of the strap. Complexes $1 \mathbf{b F e}^{\mathrm{II}}$ (Figure 6b ) and $3 \mathrm{Fe}^{\mathrm{III}}$ (Figure 6c) were also characterized by X-ray crystallography, the latter being a side-product of the synthesis of $\mathbf{1 b F e}^{\mathbf{I I}}$ in which the decarboxylation of the malonic acid moiety was observed. As these three structures have already been reported and discussed in details, ${ }^{19,20}$ we discuss them as definite proof of the various possible coordination patterns offered by these ligands.

The same $\mathrm{W}$-shape of the distal strap is also found in complex $\mathbf{1 b F e} \mathbf{e}^{\mathrm{II}}$ bearing an overhanging malonic acid. However, the X-ray structure of this complex led to a rather unexpected structure (Figure 6b). Indeed, in $\mathbf{1 b F e} \mathbf{e}^{\mathrm{II}}$ the strap is flexible enough to allow axial coordination of one carboxylic acid group to the iron center with a $\mathrm{Fe}-\mathrm{O} 4$ bond length of $2.017 \AA$. This bond length can be considered too short for an iron(II) porphyrin as usual Fe-O bond lengths encountered for iron(II) porphyrins vary from $2.121 \AA$ for $\left(\mathrm{F}_{8} \mathrm{TPP}\right) \mathrm{Fe}^{\mathrm{II}}(\mathrm{CO})(\mathrm{THF})^{34}$ to $2.127 \AA$ for the same complex obtained from deuteroporphyrin. ${ }^{35}$ In $\left(\mathrm{F}_{8} \mathrm{TPP}\right) \mathrm{Fe}^{\mathrm{II}}(\mathrm{THF})_{2}$, this bond length was found to be $2.314 \AA .{ }^{34}$ However, one must keep in mind that in $\mathbf{1 b F e}^{\mathbf{I I}}$, both axial ligands are intramolecular and embedded on preorganized straps. In other terms, the axial ligands are not totally free as they are in the above cited complexes. As the X-ray structure of $\mathbf{3 F e} \mathrm{e}^{\mathrm{III}}$, the iron(III) decarboxylated counterpart of $\mathbf{1 b F e} \mathrm{e}^{\mathrm{II}}$, has been concomitantly reported (see below), it would be difficult to attribute "an iron(III) structure" to $\mathbf{1 b F e} \mathbf{e}^{\text {II }}$. The O3 and O1 atoms have a separation of $2.478 \AA$, indicating the presence of a strong hydrogen bond between the two carboxylic acids, as in the free-base 1b. To the best of our knowledge, this is the first example of a six-coordinate iron(II) with both an axially-bound carboxylic group and a pyridine ligand. Furthermore, we have found that it is a high-spin $(S=2)$ paramagnetic complex as verified by solid state magnetic measurements performed under anaerobic conditions $\left(4.1 u_{\mathrm{B}}\right)$. As additional proof, the crystal structure of the iron(III) decarboxylated counterpart $\mathbf{3 F} \mathbf{F}^{\mathrm{III}}$ (Figure 6c) clearly indicates that it is a five-coordinate complex with an iron-bound carboxylate ligand $\mathrm{O} 2-\mathrm{Ci}-\mathrm{O} 1$ with the metal lying $0.532 \AA$ above the main porphyrin plane. 


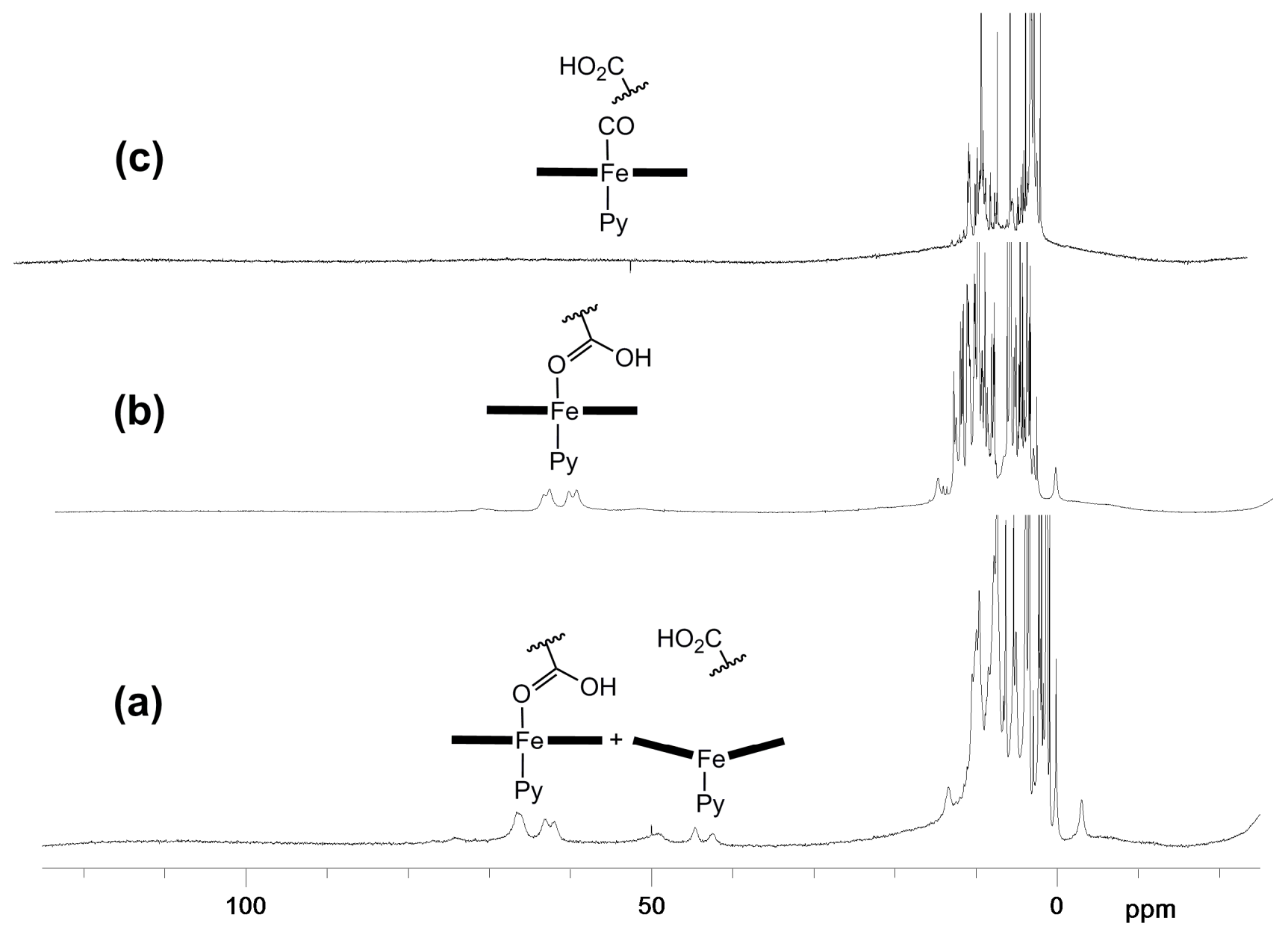

Figure 7

We have also characterized $\mathbf{1 b F e} \mathbf{e}^{\text {II }}$ by ${ }^{1} \mathrm{H}$ NMR spectroscopy. For this, a freshly prepared solution of the complex in $\mathrm{CDCl}_{3}$ was prepared in a Young NMR tube and the spectrum was recorded (Figure 7a). A paramagnetic feature is clearly visible in the spectrum near $50 \mathrm{ppm}$ which is a typical pattern of a five-coordinate high-spin ferrous complex. ${ }^{36}$ It is noteworthy that signals also appear between 60 and 70 ppm, suggesting that this spectrum may involve a mixture of the two paramagnetic complexes. In addition, the signals between 40 and 50 ppm disappear when a spectrum is recorded at least one day later (Figure 7b), indicating that the initial mixture of two paramagnetic complexes converts to a single unknown paramagnetic complex which is unlikely to be a five-coordinate complex. Again, to rule out 
any possible oxidations, the sample was exposed to a $\mathrm{CO}$ atmosphere and a third NMR spectrum was recorded (Figure 7c). The latter indicates that the paramagnetic complex binds $\mathrm{CO}$ to form the expected diamagnetic carbonyl complex. In light of this experiment and considering the particular structure of $\mathbf{1 b F e} \mathbf{e}^{\mathbf{I I}}$, we attributed this behavior to the intramolecular coordination of an overhanging carboxylic group on the iron atom as a second axial ligand. This evolution could be attributed as well to the decoordination of the nitrogen base leading to a ferrous four-coordinate paramagnetic complex with no axial ligand $(S=1)$. However, the latter type of complex exhibits a different paramagnetic pattern with the $\beta$-pyrrolic signals resonating usually close to $0 \mathrm{ppm}^{37,38}$ and sometimes up to $8 \mathrm{ppm}$. $^{39}$ These values are inconsistent with the downfield shifted signals at 50 ppm observed for $\mathbf{1 b F e} \mathbf{e}^{\mathbf{I I}}$.

However, the most important observation of complex $\mathbf{1 b F e} \mathbf{e}^{\mathbf{I I}}$ is that it binds dioxygen and CO. This implies that one of the axial ligands can be displaced when small molecules bind. Although we have no definite proof of the identity of the ligand which comes off, in light of the high affinity of nitrogen bases as pyridine or imidazole for iron(II) and their basic character, it is unlikely that a carboxylic acid group would reach the same affinity. Accordingly, and despite the rather short apical Fe-O4 distance (2.017 $\AA$ ), the oxygen atom $\mathrm{O} 4$ and therefore the carboxylic acid $\mathrm{O}_{4} \mathrm{C}_{\mathrm{o}} \mathrm{O} 3$ is loosely bound to iron and we attribute the specific behavior of $\mathbf{1 b F e ( I I ) ~ u p o n ~ g a s ~ b i n d i n g ~ t o ~ t h e ~ d e c o o r d i n a t i o n ~ o f ~ t h e ~ c a r b o x y l i c ~ a c i d ~}$ rather than that of the pyridine. This behavior rationalizes why we were not able to directly measure the equilibrium constant by the usual quantitative gas binding method described in the supporting information as it requires a single equilibrium as $\mathrm{L}-\mathrm{PFe}^{\mathrm{II}}+\mathrm{O}_{2}$ in equilibrium with $\mathrm{L}-\mathrm{PFe} \mathrm{II}^{\mathrm{II}}-\mathrm{O}_{2}$. In the case of $\mathbf{1 b F e} \mathbf{e}^{\mathrm{II}}$, which is six-coordinate, the decoordination of one axial ligand is required to allow dioxygen binding. Therefore, we have chosen to calculate the equilibrium rate from the kinetics rates which can be measured by flash photolysis. In Figure S3 (supporting information), the plots of the $k_{\mathrm{obs}}$ values determined by rebinding of $\mathrm{O}_{2}$ after photolysis against the dissolved oxygen concentration show the clear direct proportion, which determines the $k^{\mathrm{on}} \mathrm{O}_{2}$ value. However, the $\mathrm{y}$-intercept of the plots in the case of $\mathbf{1 b F e}$ II contains the rate constants for equilibrium of intramolecular sixth coordination, especially the intramolecular association rate of the sixth ligand (see Scheme S1, supporting 
information). To avoid any confusion, we define the rate constant determined by the y-section of the plots as an apparent dissociation rate constant, $k^{\text {off }}{ }_{\mathrm{O} 2}$. By this approach, the upper limit of $k_{\mathrm{O} 2}^{\text {off }}$ and lower limit of apparent $K_{\mathrm{O} 2}$ were determined. The determined association and dissociation rates of dioxygen via laser flash photolysis are gathered in Table 2.

Table 2

\begin{tabular}{|c|c|c|c|c|c|c|c|}
\hline Compounds & $\mathbf{M b}^{40}$ & $\begin{array}{l}\text { Hb } \\
\text { Ascaris }^{41}\end{array}$ & $\begin{array}{l}\text { FeMedPoc } \\
(1-M e I m)^{42}\end{array}$ & $1 \mathrm{aFe}^{\mathrm{II}}$ & $1 \mathrm{bFe} \mathrm{e}^{\mathrm{II}}$ & $2 \mathrm{aFe}^{\mathrm{II}}$ & $2 \mathrm{bFe} \mathrm{e}^{\mathrm{II}}$ \\
\hline conditions & $\begin{array}{l}\text { Water, } \\
25^{\circ} \mathrm{C}\end{array}$ & $\begin{array}{l}0.1 \mathrm{M} \\
\text { phosphate, } \\
20{ }^{\circ} \mathrm{C}\end{array}$ & $\begin{array}{l}\text { Toluene, } \\
25^{\circ} \mathrm{C}\end{array}$ & $\begin{array}{l}\text { Benzene, } \\
25{ }^{\circ} \mathrm{C}\end{array}$ & $\begin{array}{l}\text { Benzene, } \\
25^{\circ} \mathrm{C}\end{array}$ & $\begin{array}{l}\text { Benzene, } \\
25^{\circ} \mathrm{C}\end{array}$ & $\begin{array}{l}\text { Benzene, } \\
25^{\circ} \mathrm{C}\end{array}$ \\
\hline$K_{\mathrm{O} 2}, \mathrm{M}^{-1}$ & $10^{8}$ & $3.7 \times 10^{8}$ & $2.2 \times 10^{5}$ & $6.1 \times 10^{4(a)}$ & $>9 \times 10^{3(\mathrm{~b})}$ & $5.3 \times 10^{5(a)}$ & $7.7 \times 10^{7 \text { (a) }}$ \\
\hline$P_{1 / 2}{ }^{\mathrm{O} 2}$, torr & $0.37-1$ & $2 \times 10^{-3}$ & 0.36 & 1 & $<9.3^{(\mathrm{c})}$ & $10^{-1}$ & $10^{-3}$ \\
\hline$k^{\mathrm{on}}, \mathrm{M}^{-1} \mathrm{~s}^{-1}$ & $2 \times 10^{7}$ & $1.5 \times 10^{6}$ & $2 \times 10^{6}$ & --- & $9.0 \times 10^{6}$ & --- & $>1 \times 10^{8}$ \\
\hline$k^{\mathrm{off}}{ }_{\mathrm{O} 2}, \mathrm{~s}^{-1}$ & 20 & $4 \times 10^{-3}$ & 9 & --- & $<1 \times 10^{3(\mathrm{~d})}$ & --- & $>1.3$ \\
\hline
\end{tabular}

By analyzing the results of Table 2, it is seen that the two series of complexes $\mathbf{1}$ and $\mathbf{2}$ do not behave the same way. In the $\alpha \alpha \beta \beta$ conformation, the ester compound 1aFe in which the sixth-coordination site remains available, exhibits a dioxygen affinity slightly lower than that of FeMedPoc(1-MeIm) or Mb. For $1 \mathbf{b F e}$ to achieve dioxygen binding, the bound distal carboxylic acid must be released from coordination. However, the dioxygen binding constant is not significantly different as it was evaluated to be at least of $9 \times 10^{3} \mathrm{M}^{-1}$. This could be reflected by the $k^{\text {on }}$ 2 value which was found in the same range as that of FeMedPoc(1-MeIm) and natural hemoproteins. This result is not inconsistent as the binding of dioxygen in the latter synthetic model cannot be dramatically increased by the presence of a pocket on the distal side. 
The interesting result appears with the $\alpha \beta \alpha \beta$ series in which the ester complex 2aFe exhibits a dioxygen affinity comparable to that of FeMedPoc(1-MeIm) or Mb. At this point, it is not known if this is due to the less pronounced steric effect of the distal strap in this series or to another type of interaction. However, for the carboxylic acid complex $\mathbf{2 b F e}$, the dioxygen affinity is increased by two orders of magnitude. Interestingly, this increase in affinity could be caused by the high $k_{\mathrm{O} 2}^{\mathrm{on}}$ value which is at least equal to $10^{8} \mathrm{M}^{-1} \mathrm{~s}^{-1}$. This is consistent with an accessible vacant binding site or hydrogen bonding support for the binding of dioxygen. The same type of polar interactions can be found in $\mathbf{2 b F e}$ as in $\mathbf{1 b F e}$. However, in contrast to $\mathbf{1 b F e}, \mathbf{2 b F e}$ is a five-coordinate complex with a sixth coordination site remaining vacant for binding of dioxygen. Second, from the X-ray structure of $\mathbf{2 a}$, we know that the carboxyl group in the $\alpha \beta \alpha \beta$ series is located slightly closer to the center than it is in the $\alpha \alpha \beta \beta$ series. These two structural features appear to be responsible for the difference in dioxygen affinity. Whether the increase in the dioxygen affinity is due to dipolar interactions, hydrogen bonding, or reduced steric hindrance remains uncertain and requires further investigation. It is expected that additional solid state crystal structures will be required to identify the major factor.

\section{CONCLUSION}

We have synthesized and characterized a series of four complexes obtained from two isomers of the same two potential axial ligands delivered by pre-organized, yet flexible straps. These two axial ligands are a pyridine base and either an ethyl malonyl ester group or a malonic carboxylic acid. From a structural point of view, we have characterized three free-base ligands together with three iron complexes. In the case of the $\alpha \alpha \beta \beta$ geometry, the ferrous complex $\mathbf{1 b F e ( I I )}$ adopts an unexpected sixcoordinate coordination sphere by intramolecular coordination of a carboxylic acid on the distal side. However, it remains able to bind gaseous molecules after release of this axial carboxylic acid. On the other hand, the three other complexes exhibit the expected five-coordinate coordination sphere suitable 
for the binding of gaseous molecules. For $\mathbf{1 b F e}(\mathbf{I I})$ the intramolecular coordination behavior of one overhanging carboxylic acid above the iron ion clearly indicates that the strap is too flexible to preserve a free coordination site for dioxygen binding. This prevents direct spectroscopic measurement of the binding constant which was therefore calculated from the kinetic rates. The required release of the carboxylic acid from the iron iron center prior to binding of dioxygen is somehow reflected by a $k^{\text {on }}{ }_{2}$ value at least one order of magnitude smaller than that of its analogous counterpart in the other $\alpha \beta \alpha \beta$ geometry. As the kinetic data lead only to an upper limit of the calculated equilibrium rate, we can only conclude that the dioxygen affinity of $\mathbf{1 b F e ( I I )}$ is roughly the same as that of its ester precursor.

Conversely, in the $\alpha \beta \alpha \beta$ series, we have measured an increase of two orders of magnitude of the equilibrium rate for dioxygen binding when comparing the precursor overhanging ester complex to the overhanging carboxylic acid complex $2 \mathbf{b F e}(\mathbf{I I})$. While the structure of the latter prevents any direct interaction between the metal cation and the carboxylic acid groups, it could allow formation of a hydrogen bond between one of the carboxylic acid groups and the superoxo complex, consistent with the observed increase of dioxygen affinity. However, this hypothesis would need to be validated by the an X-ray structure having sufficient resolution to identify the dioxygen adduct.

\section{ACKNOWLEDGMENT}

The authors thank the CNRS for financial support as well as the MENRT for a grant for IH. The bilateral France-Japan ANR-JST program TMOL "Molecular Technology" project "MECANO” ANR14-JTIC-0002-02 is acknowledged for providing a grant.

SUPPORTING INFORMATION AVAILABLE: crystallographic CIF files of 1b (CCDC 792739), 2a (CCDC 993981), and 4 (CCDC 792738). This material is available free of charge via the Internet at http://pubs.acs.org. 


\section{SCHEME AND FIGURE CAPTIONS}

Scheme 1. Synthesis of bis-strapped dioxygen carriers $\mathbf{1 a}$ and $\mathbf{1 b}$ bearing overhanging ethyl ester and carboxylic acid groups, respectively, in the $\alpha \alpha \beta \beta$ topology. (i) diethylmalonate, EtONa, $\mathrm{CH}_{2} \mathrm{Cl}_{2}, 2 \mathrm{~h}$, 60\%; (ii) $C$-pyridin-3-yl-methylamine, $\mathrm{NaI}, \mathrm{K}_{2} \mathrm{CO}_{3}$, reflux THF, 3 days, $85 \%$; (iii) glovebox, <2 ppm $\mathrm{O}_{2}, \mathrm{FeBr}_{2}$, reflux THF, overnight, quantitative yield; (iv) $\mathrm{BBr}_{3}, \mathrm{CH}_{2} \mathrm{Cl}_{2}$, room temperature, overnight, 56\%. "i" and "o" indicate the in and out positions of the respective ester groups. (Compounds on grey background were characterized by X-Ray crystallography).

Scheme 2. Synthesis of bis-strapped dioxygen carriers $\mathbf{2 a}$ and $\mathbf{2 b}$ bearing overhanging ethyl ester and carboxylic acid groups, respectively, in the $\alpha \beta \alpha \beta$ topology. (i) diethylmalonate, EtONa, $\mathrm{CH}_{2} \mathrm{Cl}_{2}, 2 \mathrm{~h}$, 62\%; (ii) toluene, $80{ }^{\circ} \mathrm{C}, 48 \mathrm{~h}, 70 \%$; (iii) $C$-pyridin-3-yl-methylamine, $\mathrm{NaI}, \mathrm{K}_{2} \mathrm{CO}_{3}$, reflux THF, 2 days, 30\%; (iv) $\mathrm{BBr}_{3}, \mathrm{CH}_{2} \mathrm{Cl}_{2}$, room temperature, overnight, 56\%; (v) glovebox, <2 ppm $\mathrm{O}_{2}, \mathrm{FeBr}_{2}$, reflux THF, overnight, quantitative yield. (Compound on grey background was characterized by X-Ray crystallography).

Figure 1. Design of the two isomeric series considered in this work, depicted with the myoglobin coordination site. (Red and blue circles indicate hinges ; o and i indicate the "out" and "in" positions of the R group).

Figure 2. Oak Ridge thermal ellipsoid plot ORTEP (30\% thermal ellipsoids) representation of the X-ray structure of free-base porphyrin 4.

Figure 3. ORTEP (30\% thermal ellipsoids) view of the X-ray structure of free-base porphyrin $\mathbf{1 b}$.

Figure 4. ORTEP (30\% thermal ellipsoids) representation of the X-ray structure of free-base porphyrin 2a. (a) perspective representation, (b) edge-on view.

Figure 5. ${ }^{1} \mathrm{H}$ NMR spectra $\left(\mathrm{CDCl}_{3}, 500 \mathrm{MHz}, 313 \mathrm{~K}\right)$ of a) $\mathbf{1 a F e}{ }^{\mathbf{I I}}$, b) spectrum a) $+\mathrm{O}_{2}$, c) spectrum b) $+\mathrm{CO}$.

Figure 6. Ball and stick views of the previously reported X-ray structure of complexes (a) 1aFe(II), (b) $1 \mathrm{bFe}(\mathrm{II})$, and (c) 3Fe(III). 
Figure 7. ${ }^{1} \mathrm{H}$ NMR spectra $\left(\mathrm{CDCl}_{3}, 500 \mathrm{MHz}, 298 \mathrm{~K}\right)$ of a) $\mathbf{1 b F e} \mathbf{e}^{\mathrm{II}}$, b) spectrum a) $24 \mathrm{~h}$ later, c) spectrum b) + CO.

Table 1. Details of data collection, structure solution and refinement for models compounds $\mathbf{4}, \mathbf{1 b}$, and 2a.

Table 2. Equilibrium and kinetic data for selected hemoproteins and models together with those of this work. a) measured under equilibrium conditions b) evaluated from kinetic rates according to the equation: $K=k_{\mathrm{O} 2}^{\mathrm{on}} / k^{\mathrm{off}}{ }_{\mathrm{O} 2}$. c) Dioxygen solubility in benzene at $25{ }^{\circ} \mathrm{C}: 9.1 \mathrm{x} 10^{-3} \mathrm{M} \mathrm{atm}^{-1} \cdot{ }^{43}$ FeMedPoc(1-MeIm) represents a synthetic model with a medium sized pocket on one side but no intramolecular nitrogen base on the other side. Hence, 1-methyl imidazole is used as a fifth ligand. d) $k^{\text {off }}{ }_{\mathrm{O} 2}$ 


\section{REFERENCES}

(1) Jameson, G. B.; Ibers, J. A., Biological and Synthetic Dioxygen Carriers. In Bioinorganic Chemistry, Bertini, I.; Gray, H. B.; Lippard, S. J.; Valentine, J. S., Eds. University Science Books: Mill Valley, California, 1994; pp 167-251 and references herein.

(a) Collman, J. P.; Brauman, J. I.; Halbert, T. R.; Suslick, K. S. Nature of $\mathrm{O}_{2}$ and CO binding to metalloporphyrins and heme proteins. Proc. Natl. Acad. Sci. U.S.A. 1976, 73, 3333-3337. (b) Collman, J. P.; Herrmann, P. C.; Fu, L.; Eberspacher, T. A.; Eubanks, M.; Boitrel, B.; Hayoz, P.; Zhang, X.; Brauman, J. I.; Day, V. W. Aza-crown-Capped Porphyrin Models of Myoglobin: Studies of the Steric Interactions of Gas Binding. J. Am. Chem. Soc. 1997, 119, 3481-3489.

(3) (a) Li, X.-Y.; Spiro, T. G. Is Bound CO Linear or Bent in Heme Proteins? Evidence from Resonance Raman and Infrared Spectroscopic Data. J. Am. Chem. Soc. 1988, 110, 6024-6033. (b) Ray, G. B.; Li, X. Y.; Ibers, J. A.; Sessler, J. L.; Spiro, T. G. How Far Can Proteins Bend the FeCO Unit? Distal Polar and Steric Effects in Heme Proteins and Models. J. Am. Chem. Soc. 1994, 116, 162-176. (c) Spiro, T. G.; Kozlowski, P. M. Is the CO adduct of myoglobin bent, and does it matter? Acc. Chem. Res. 2001, 34, 137-144.

(4) Pauling, L. Nature of the Iron-Oxygen Bond in Oxyhaemoglobin. Nature 1964, 203, 182-183.

(5) Phillips, S. E. V.; Schoenborn, B. P. Neutron diffraction reveals oxygen-histidine hydrogen bond in oxymyoglobin. Nature 1981, 292, 81-82.

(6) Momenteau, M.; Reed, C. A. Synthetic Heme Dioxygen Complexes. Chem. Rev. 1994, 94, 659698.

(7) (a) Collman, J. P.; Gagne, R. R.; Halbert, T. R.; Marchon, J.-C.; Reed, C. A. Reversible Oxygen Adduct Formation in Ferrous Complexes Derived from a "Picket Fence" Porphyrin. A Model for Oxymyoglobin. J. Am. Chem. Soc. 1973, 95, 7868-7870. (b) Collman, J. P.; Gagne, R. R.; Reed, C. A.; 
Halbert, T. R.; Lang, G.; Robinson, W. T. "Picket Fence Porphyrins." Synthetic Models for Oxygen Binding Hemoproteins. J. Am. Chem. Soc. 1975, 97, 1427-1439.

(8) Hashimoto, T.; Dyer, R. L.; Crossley, M. J.; Baldwin, J. E.; Basolo, F. Ligand, Oxygen, and Carbon Monoxide Affinities of Iron(II) Modified "Capped" Porphyrins. J. Am. Chem. Soc. 1982, 101, $4762-4763$.

(9) Collman, J. P.; Brauman, J. I.; Collins, T. J.; Iverson, B. L.; Lang, G.; Pettman, R. B.; Sessler, J. L.; Walter, M. A. Synthesis and Characterization of the "Pocket" Porphyrins. J. Am. Chem. Soc. 1983, 105, 3038-3052.

(10) Tétreau, C.; Lavalette, D.; Momenteau, M.; Fischer, J.; Weiss, R. Structure-reactivity relationship in oxygen and carbon monoxide binding with some heme models. J. Am. Chem. Soc. 1994, $116,11840-11848$.

(11) (a) Momenteau, M.; Mispelter, J.; Loock, B.; Lhoste, J.-M. Both-faces Hindered Porphyrins. Part 3. Synthetis and Characterization of internally Five-co-ordinated Iron(II) Basket-handle Porphyrins derived from 5,10,15,20-Tetrakis(o-aminophenyl) porphyrin. J. Chem. Soc., Perkin Trans. I 1985, 221231. (b) Rose, E.; Boitrel, B.; Quelquejeu, M.; Kossanyi, A. Binding of oxygen and carbon monoxide to heme protein models. Tetrahedron Lett. 1993, 34, 7267-7270. (c) Richard, P.; Rose, E.; Boitrel, B. Characterization and Crystal Structure of a Chiral Ruffled Basket-Handle Porphyrin. Inorg. Chem. 1998, 37, 6532-6534.

(12) (a) Michaudet, L.; Richard, P.; Boitrel, B. Synthesis and x-ray characterization of a new biscrown ether porphyrin. Tetrahedron Lett. 2000, 41, 8289-8292. (b) Didier, A.; L'Her, M.; Boitrel, B. Substituted tren-capped porphyrins: Probing the influence of copper in synthetic models of cytochrome c oxidase. Org. Biomol. Chem. 2003, 1, 1274-1276.(c) Ruzié, C.; Even, P.; Ricard, D.; Roisnel, T.; Boitrel, B. $\mathrm{O}_{2}$ and CO Binding to Tetraaza-Tripodal-Capped Iron(II) Porphyrins. Inorg. Chem. 2006, 45, $1338-1348$. 
(13) Tani, F.; Matsu-ura, M.; Ariyama, K.; Setoyama, T.; Shimada, T.; Kobayashi, S.; Hayashi, T.; Matsuo, T.; Hisaeda, Y.; Naruta, Y. Iron twin-coronet porphyrins as models of myoglobin and hemoglobin: Amphibious electrostatic effects of overhanging hydroxyl groups for successful $\mathrm{CO} / \mathrm{O}_{2}$ discrimination. Chem. Eur. J. 2003, 9, 862-870.

(14) Mispelter, J.; Momenteau, M.; Lavalette, D.; Lhoste, J.-M. Hydrogen-Bond Stabilization of Oxygen in Hemoprotein Models. J. Am. Chem. Soc. 1983, 105, 5165-5166.

(15) Gerothanassis, I. P.; Momenteau, M. ${ }^{17} \mathrm{O}$ NMR Spectroscopy as a Tool for Studying Synthetic Oxygen Carriers Related to Biological Systems: Application to a Synthetic Single-Face Hindered Iron Porphyrin-Dioxygen Complex in Solution. J Am Chem Soc 1987, 109, 6944-6947.

(16) Dube, H.; Kasumaj, B.; Calle, C.; Saito, M.; Jeschke, G.; Diederich, F. Direct Evidence for a Hydrogen Bond to Bound Dioxygen in a Myoglobin/hemoglobin Model System and in Cobalt Myoglobin by Pulse-EPR Spectroscopy. Angew. Chem. Int. Ed. 2008, 47, 2600-2603.

(17) Momenteau, M.; Rougée, M.; Loock, B. Five-Coordinate Iron-Porphyrin as a Model for the Active Site of Hemoproteins. Eur. J. Biochem. 1976, 71, 63-76.

(18) Mandon, D.; Ott-Woelfel, F.; Fischer, J.; Weiss, R.; Bill, E.; Trautwein, A. X. Structure and Spectroscopic Properties of Five-Coordinate (2-Methylimidazo1ato)- and Six-Coordinate (Imidazole) (imidazolato)iron(II) "Picket-Fence" Porphyrins. Inorg. Chem. 1990, 29, 2442-2447.

(19) Hijazi, I.; Roisnel, T.; Fourmigué, M.; Weiss, J.; Boitrel, B. Coordination Studies of BisStrapped-Hanging-Carboxylate Porphyrins. X-Ray Characterization of a Five-coordinate Iron(II) complex with a buit-in axial base. Inorg. Chem. 2010, 49, 3098-3100.

(20) Hijazi, I.; Roisnel, T.; Even-Hernandez, P.; Furet, E.; Halet, J.-F.; Cador, O.; Boitrel, B. Characterization of a Six-coordinate Ferrous High-spin Heme with both Intramolecular Axial Carboxylic Acid and Pyridine. J. Am. Chem. Soc. 2010, 132, 10652-10653. 
(21) Halime, Z.; Balieu, S.; Lachkar, M.; Roisnel, T.; Richard, P.; Boitrel, B. Functionalization of porphyrins: mechanistic insights, conformational studies, and structural characterizations. Eur. J. Org. Chem. 2006, 1207-1215.

(22) Balieu, S.; Hijazi, I.; Motreff, N.; Lachaud, F.; Even-Hernandez, P.; Boitrel, B. Steric Decompression of Picket-Strapped Porphyrins for the Synthesis of Side-Differentiated Chelates. Org. Lett. 2010, 12, 8-11.

(23) Altomare, A.; Burla, M. C.; Camalli, M.; Cascarano, G.; Giacovazzo, C.; Guagliardi, A.; Moliterni, A. G. G.; Polidori, G.; Spagna, R. SIR97: a new tool for crystal structure determination and refinement. J. Appl. Crystallogr. 1999, 32, 115-119.

(24) Sheldrick, G. M. SHELX97, Programs for Crystal Structure Analysis (release 97-2). Institüt für Anorganische Chemie der Universiät: Göttingen, Germany, 1998.

(25) Farrugia, L. J. WinGX suite for small-molecule single-crystal crystallography. J. Appl. Crystallogr. 1999, 32, 837-838.

(26) Didier, A.; Michaudet, L.; Ricard, D.; Baveux-Chambenoit, V.; Richard, P.; Boitrel, B. A versatile and convenient method for the functionalization of porphyrins. Eur. J. Org. Chem. 2001, 19171926.

(27) Halime, Z.; Lachkar, M.; Roisnel, T.; Richard, P.; Boitrel, B. Structural and Coordination Studies of "Pearl Oysterlike" Porphyrins. Inorg. Chem. 2007, 46, 6338-6346.

(28) Halime, Z.; Lachkar, M.; Roisnel, T.; Furet, E.; Halet, J.-F.; Boitrel, B. Bismuth and lead hanging-carboxylate porphyrins: an unexpected homobimetallic lead(II) complex. Angew. Chem., Int. Ed. 2007, 46, 5120-5124.

(29) The mean planes of both straps are calculated considering all the atoms of the strap but those of the ethoxycarbonyl, carboxy or methyl pyridine groups.

(30) Lindsey, J. Increased Yield of a Desired Isomer by Equilibria Displacement on Binding to Silica Gel, Applied to meso-Tetrakis (o-aminophenyl) porphyrin. J. Org. Chem. 1980, 45, 5215-5215. 
(31) Kim, E.; Helton, M. E.; Lu, S.; Moenne Loccoz, P.; Incarvito, C. D.; Rheingold, A. L.; Kaderli, S.; Zuberbuhler, A. D.; Karlin, K. D. Tridentate copper ligand influences on heme-peroxo-copper formation and properties: Reduced, superoxo, and mu-peroxo iron/copper complexes. Inorg. Chem. 2005, 44, 7014-7029.

(32) Shirazi, A.; Goff, H. M. Characterization of Superoxide-Metalloporphyrin Reaction Products: Effective Use of Deuterium NMR Spectroscopy. J. Am. Chem. Soc. 1982, 104, 6318-6322.

(33) Brzezinski, P.; Malmström, B. G. The reduction of cytochrome c oxidase by carbon monoxide. FEBS Lett. 1985, 187, 111-114.

(34) Thompson, D. W.; Kretzer, R. M.; Lebeau, E. L.; Scaltrito, D. V.; Ghiladi, R. A.; Lam, K. C.; Rheingold, A. L.; Karlin, K. D.; Meyer, G. J. Synthesis, characterization, and laser flash photolysis reactivity of a carbonmonoxy heme complex. Inorg. Chem. 2003, 42, 5211-5218.

(35) Scheidt, W. R.; Faller, K. J.; Fons, M.; Mashiko, T.; Reed, C. A. A (Carbonmonoxy)heme Complex with a Weak Proximal Bond. Molecular Stereochemistry of Carbonyl(deuteroporphinato) (tetrahydrofuran)iron(II). Biochemistry 1981, 20, 3653-3657.

(36) Goff, H.; Mar, G. N. L. High-Spin Ferrous Porphyrin Complexes as Models for Deoxymyoglobin and -hemoglobin. A Proton Nuclear Magnetic Resonance Study. J. Am. Chem. Soc. 1977, 99, 6599-6606.

(37) Goff, H.; Mar, G. N. L.; Reed, C. A. Nuclear Magnetic Resonance Investigation of Magnetic and Electronic Properties of "Intermediate spin" Ferrous Porphyrin Complexes. J. Am. Chem. Soc. 1977, 99, 3641-3646.

(38) Stäubli, B.; Fretz, H.; Piantini, U.; Woggon, W.-D. Synthetic Models of the Active Site of Cytochrome P-450. The Synthesis of a Doubly-Bridged Iron(II)-Porphyrin Carrying a Tightly Bound Thiolate Ligand. Helv. Chim. Acta 1987, 70, 1173-1193.

(39) Richard, P.; Rose, E.; Boitrel, B. Characterization and Crystal Structure of a Chiral Ruffled Basket-Handle Porphyrin. Inorg. Chem 1998, 37, 6532-6534. 
(40) Antonini, E. Brunori, M. in Hemoglobin and Myoglobin and their Reactions with Ligands, North Holland, Amsterdam, 1971.

(41) Wittenberg, J. B.; Appleby, C. A.; Wittenberg, B. A. The kinetics of the reactions of leghemoglobin with oxygen and carbon monoxide. J. Biol. Chem. 1972, 247, 527-531.

(42) Collman, J. P.; Brauman, J. I.; Iverson, B. L.; Sessler, J. L.; Morris, R. M.; Gibson, Q. H. O 2 and CO Binding to Iron(II) Porphyrins: A Comparison of the "Picket Fence" and "Pocket" Porphyrins. J. Am. Chem. Soc. 1983, 105, 3052-3064.

(43) Battino, R. Ed., IUPAC Solubility Data Series, Vol. 7, Oxygen and Ozone, Pergamon Press, Oxford, England, 1981. 
SYNOPSIS TOC AND GRAPHICS

Dioxygen binding is studied for two isomers of ferrous bis-strap porphyrins bearing an overhanging malonic acid group. When compared with their ethyl ester precursors, in the $\alpha \alpha \beta \beta$ series, one of the carboxylic acid is coordinated to the iron and must be displaced to allow dioxygen binding. In the other $\alpha \beta \alpha \beta$ series, such a coordination of the carboxylic acid is not possible and dioxygen affinity is significantly increased.

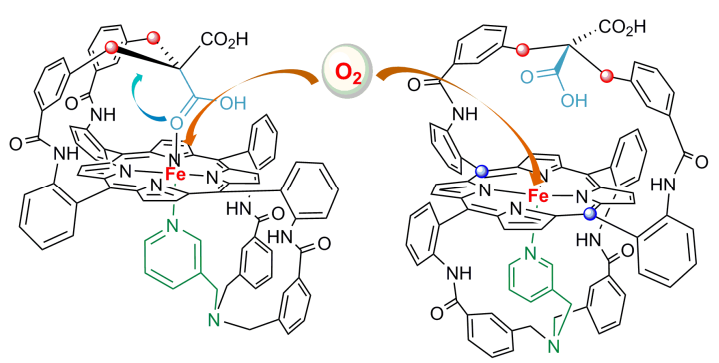

